с включением в их состав педагогов, литераторов, режиссеров, продюсеров, представителей общественности и др., занимающихся воспитанием, образованием подрастающего поколения, созданием детских фильмов и телепрограмм;

- создание специализированной кинопрокатной организации (с государственным участием) по продвижению на экраны и в видеосеть фильмов, предназначенных для детской и юношеской аудитории;

- расширение сети государственных специализированных детских кинотеатров;

- введение квот на обязательный показ фильмов для детской аудитории;

- ежегодное проведение Всероссийских конкурсов на лучший сценарий фильма для детей и юношества;

- включение в число номинаций Национальной академии кинематографических искусств и наук России номинации «Лучший детский фильм» и др.

Реализация предложенных мер, осуществляемых в пределах установленных государством лимитов бюджетного финансирования за счет перераспределения средств в пользу детского кинематографа, позволила бы в самое ближайшее время сдвинуть дело с мертвой точки. Но главное, чтобы подходы к решению этих проблем носили системный характер: от создания законодательной базы, от штучной работы по отбору проектов, получающих государственное финансирование, предоставляемое по особым нормативам, до механизмов государственной поддержки продвижения детских фильмов в киносети и на телевидении, до подготовки творческих кадров нового поколения. Пока же принятые рекомендации никакого отклика, а тем более практической реализации, не получили.

Конечно, винить в этом можно и объективные причины, которые всегда есть и будут, но они существуют для того, чтобы убедительно оправдывать такие негативные человеческие качества, как слабость, пассивность, абсолютную недальновидность и равнодушие.

ЛИТЕРАТУРА:

1. «Кинопрочесс» №4 (53)/2008.

2. Профессия - продюсер кино и телевидения. Практические подходы: үчебник для студенто

Пробессия - продюсер кино и телевидения. Практические подходы: учебник дия
вузов/под ред. В.И. Сидоренко, П.К. Оеурчикова. - М.: ЮНИТИ-ДАНА, 2010.

3. Харитонов Е. В., Щербак-Жуков А. В. На экране - Чудо: Отечественная кинофантастика
и киносказка (1909-2002):- Москва: НИИ Киноискусства; В. Секачев, 2003.

4. Киностоварь. В двух томах. Изд-во «Советская энциклопедия». М, 1966.

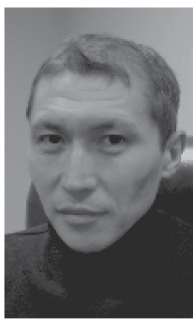

Прогнозирование коммерческого

потенциала кинопроекта на ранних

этапах фильмопроизводства

\section{С.К. Сарымсаков}

В статье обсуждается проблема убыточности производства российских игровых полнометражных кинобильмов и повышения их потребительских качеств за счет имплементации эфбективных инструментов управления кинематографическим бизнес-процессом на ранних этапах фильмопроизводства. Представлен методический инструментарий проведения прогнозной оценки коммерческого потенциала кинопроекта и процедура принятия рационального управленческого решения о иелесообразности его реализаиии в заданных параметрах ресурсного обеспечения.

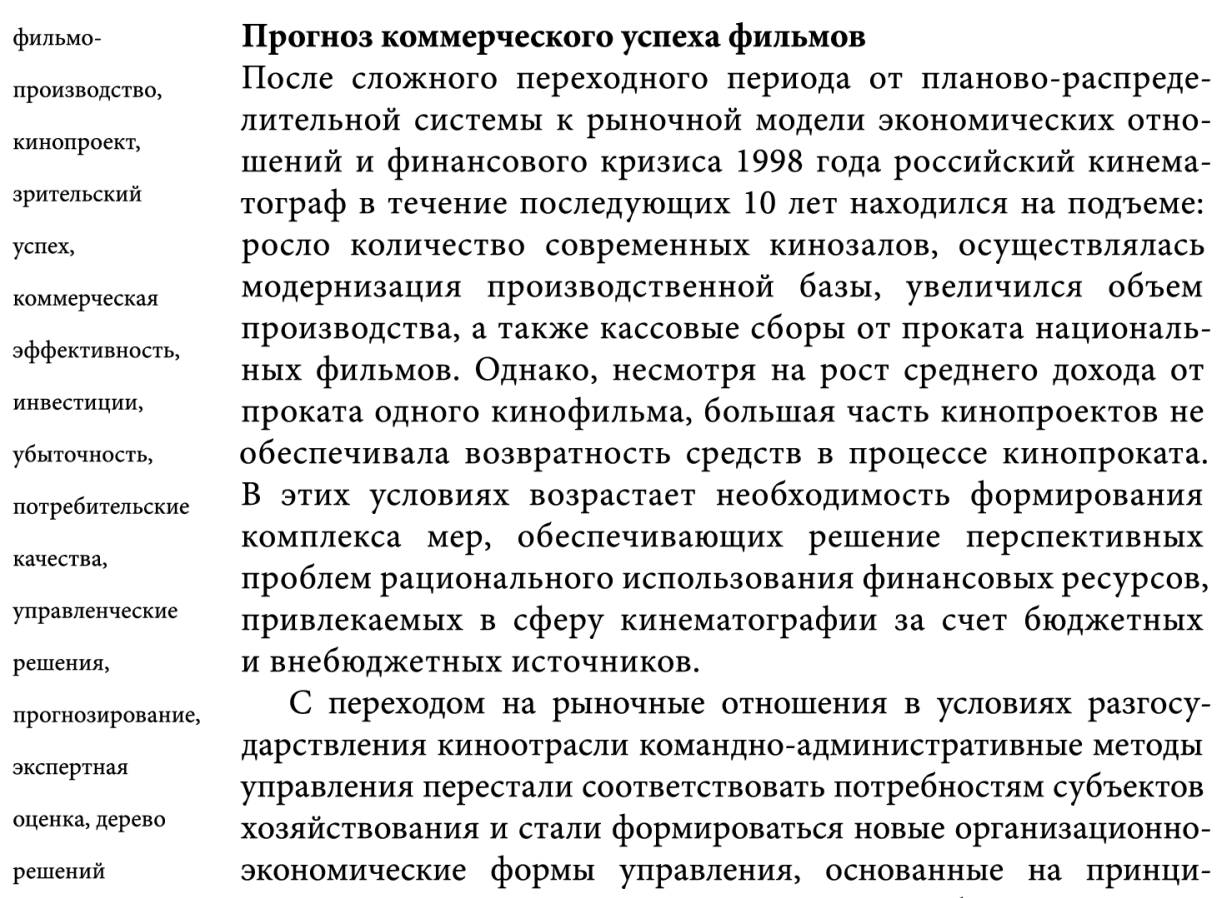
пах предпринимательства, конкуренции и свободы творчества. 
В настоящее время ключевой фигурой кинопроцесса является продюсер, который принимает решения и действует под свою ответственность с момента появления замысла фильма и до реализации кинопродукции. Его прибыль как предпринимателя определяется конкурентоспособностью созданной продукции, наличием у нее высоких потребительских свойств.

В ходе разработки кинопроекта продюсер является посредником между будущим зрителем и потенциальным инвестором, его задача заключается в том, чтобы убедить инвестора в способности кинофильма привлечь целевую аудиторию, получить ожидаемые доходы и тем самым обеспечить возврат инвестиций. Для этого необходимо проведение научно обоснованной прогнозной оценки коммерческого потенциала кинопроекта посредством социально-экономического анализа сценария на предмет исследования его соответствия формирующемуся спросу с учетом конкурентной среды и потребительского поведения, результаты которого должны служить основой для принятия аргументированного управленческого решения о целесообразности реализации кинопроекта.

Научная система прогнозирования коммерческого успеха фильмов должна основываться на результатах исследования такого явления, как кинопроцесс, а также анализе закономерностей зрительского восприятия кинопродукции. Необходимо учитывать, что кинофильм, как конечный продукт кинопроцесса, является результатом взаимодействия различных составляющих (экономических, технических, творческих), связанных между собой причинно-следственными отношениями для достижения общей цели и стремящихся к состоянию внутреннего динамического равновесия.

Создание кинофильма состоит из нескольких этапов, каждый из которых характеризуется своими организационными особенностями [8]. На первоначальном этапе создания кинофильма ключевым моментом является принятие решения о целесообразности реализации кинопроекта.

На Puc. 1 представлена типовая схема процесса разработки и принятия решения о целесообразности реализации кинопроекта. В соответствии с данной схемой процесс поиска оптимального решения показан в виде многошаговой процедуры - определенной последовательности шагов, для каждого из которых будет найдено оптимальное решение, причем оптимальность определяется влиянием на последующие шаги. Из рисунка следует, что для проведения аргументированной оценки коммерческой эффективности кинопроекта и принятия рационального решения о целесообразности реализации кинопроекта необходимо сделать прогноз в отношении доходов от реализации фильма. Другими словами, нужно провести прогнозную оценку коммерческого потенциала кинопроекта, результаты которой будут служить основой принятия обоснованных инвестиционных решений, исходя из целей данного кинопроекта, его коммерческого потенциала, художественных и других особенностей будущего фильма, а также объемов его ресурсного обеспечения. При таком подходе суть прогнозирования коммерческого потенциала кинопроекта заключается в проведении тщательного и критического анализа кинопроекта до его запуска и выработке конкретных, реалистичных предложений по повышению содержательных, художественных, зрелищных и иных характеристик будущего фильма.

\section{Инструментарий прогнозной оценки коммерческого потенциала кинопроекта}

Ниже представлены методические положения проведения прогнозной оценки коммерческого потенциала кинопроекта. Данная оценка осуществляется посредством экспертного опроса (см. Puc. 2), в связи с чем выделены следующие этапы проведения оценки:

- подготовительный этап

- этап экспертной оценки;

- этап обработки и анализа результатов экспертной оценки.

1) Проведение экспертного опроса требует выполнения комплекса подготовительных мероприятий, а именно:

- формирования группы управления экспертизой;

- выявления специалистов - кандидатов в эксперты;

- оценки компетентности экспертов.

Группа управления экспертизой. Формирование группы включает определение ее задач и функций, состава и обязанностей членов. Задача группы заключается в подготовке и проведении экспертизы, обработке, анализе и обобщении ее результатов с целью выявления мнения экспертов. Важной функцией группы является обеспечение условий для наиболее плодотворной работы экспертов - как за счет установления эффективной системы контактов экспертов с группой управления, так и внутри самой экспертной группы.

Оптимально в состав группы управления экспертизой входят: руководитель группы, специалист и технический работник. Ру- 
Схема процесса разработки и принятия решения о иелесообразности реализации кинопроекта

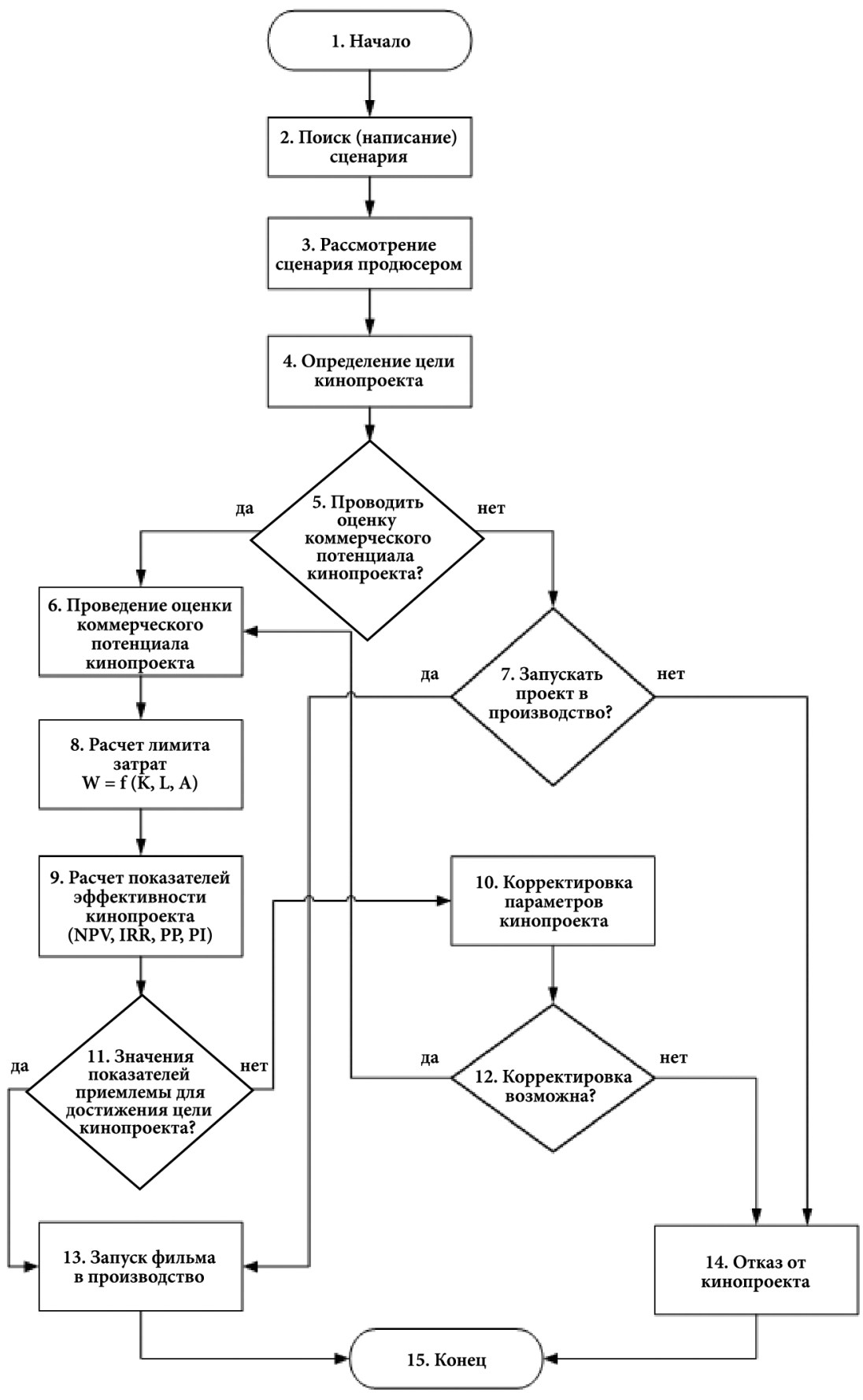

ководитель группы осуществляет общее руководство экспертизой на всех этапах, проводит инструктаж экспертов, формулирует выводы и разрабатывает заключение экспертной группы. Он должен знать методологию проведения экспертных оценок и уметь составлять алгоритмы обработки результатов опросов. Задача специалиста заключается в предоставлении экспертам необходимых данных, в анализе полученной от них информации с целью выработки Заключения. Технический работник проводит обработку полученных результатов.

Выявление множества спещиалистов. В этих целях используется метод «снежного кома» [2]. Составляется первоначальный список лиц, которые специализируются по различным направлениям исследуемого вопроса, а именно: кинодраматургия, продюсирование, редактирование, киноведение, киносоциология, дистрибьюция. Избранных таким образом лиц просят, в свою очередь, назвать известных им специалистов и т.д. - процедура проводится до тех пор, пока расширяющийся список не пополнится новыми кандидатурами. Отбор может быть прерван в случае накопления порядка 95\% повторений.

Оценка компетентности экспертов. Для проведения оценки компетентности экспертов существует два подхода. Первый подход состоит в оценке компетентности до начала экспертизы и нацелен на выбор экспертов. Второй подход заключается в определении компетентности по результатам экспертизы и нацелен на учет компетентности при обработке данных опроса, а также на отбор экспертов для будущих экспертиз.

2) Этап экспертной оценки. Данный этап начинается с уточнения объекта исследования и методики проведения оценки, согласования оценочной шкалы коммерческого успеха фильма, терминологии, а также перечня оцениваемых критериев с учетом жанра будущего фильма. Так, например, в комедии основным критерием оценки будет комизм, в драме - психологизм и социальная проблематика, в мюзикле музыкальность, в приключенческом фильме - динамичность действия и т.д.

Ниже предложен примерный перечень критериев прогнозной оценки коммерческого потенциала кинопроекта по результатам экспертной оценки первоначального списка, содержащего 27 основных элементов. Оценка производилась посредством ранжирования и последующего анализа согласованности мнений шести экспертов на основе расчета коэффициентов конкордации. В результате 23 признака признаны значимыми для проведения прогнозной оценки (см. Табл. 1). 
Puc. 2.

Схема проведения экспертного опроса

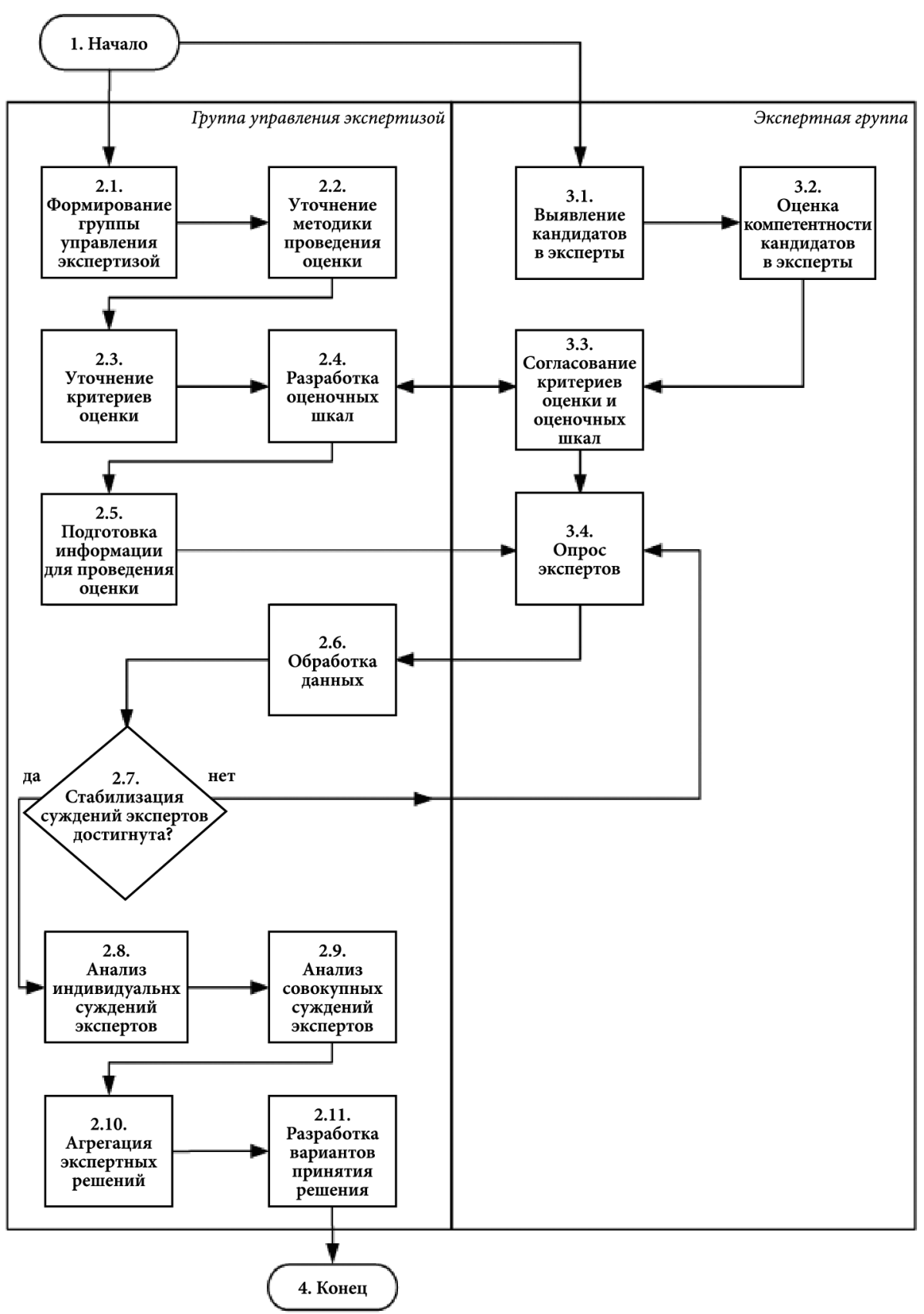

Значение коэффициента конкордации по критериям 1.1-1.10 группы «Сценарий, его конструкция и элементы структуры» составило 0,825; по критериям 2.1-2.5 «Целевая аудитория будущего фильма» - 0,822; и по критериям 3.1-3.6 «Деловая и профессиональная репутация создателей фильма» - 0,854. Полученные значения свидетельствуют о высокой согласованности мнений экспертов. Были также установлены коэффициенты относительной важности критериев или веса (Табл. 1, столбцы 2 и 3).

Информация для экспертов. Для проведения оценки экспертам предоставляется следующее: киносценарий, анализ текущего состояния кинорынка, информация о целевой аудитории фильма, расчет производственной себестоимости фильма, сведения о студии, продюсере, режиссере, актерах-исполнителях главных ролей, стратегия продвижения фильма и др.

Теперь обратимся непосредственно к самой экспертной оценке коммерческого потенциала кинопроекта. Задача экспертов провести всесторонний, критический анализ сценария и проекта в целом и на его основе определить качественные характеристики формализованных критериев оценки путем выставления баллов в соответствии с пятиступенчатой шкалой $(0,1,2,3$ или 4 балла). При этом 0 баллов - характеризует отсутствие какой-либо выраженности критерия; 1 балл - состояние слабой выраженности; 2 балла - состояние средней выраженности; 3 балла - состояние высокой выраженности; 4 балла - состояние очень высокой выраженности. Выставление баллов необходимо для анализа степени изменения мнений экспертов по сравнению с предыдущими турами.

После оценки критериев эксперт должен отнести фильм к одному из установленных уровней коммерческого успеха. Для этого предлагается следующий подход. Если, по мнению эксперта, у кинопроекта присутствует и интенсивно выражено 19 и более из 23 оцениваемых критериев (т.е. всем этим критериям эксперт присудил 4 балла), он имеет очень высокий коммерческий потенииал; если 14-18 критериев - высокий коммерческий потенииал; 9-13 критериев - средний коммерческий потенциал; 5-8 критериев - низкий коммерческий потенииал. И, наконец, если, по мнению эксперта, присутствует менее 5 критериев, то кинофильм имеет очень низкий коммерческий потенциал.

Данный подход основан на использовании вербальночисловых шкал, которые позволяют измерить степень интенсивности критериальных свойств, имеющих субъективный характер. В Табл. 2 представлена модифицированная вербальночисловая шкала Харрингтона [3] для проведения прогнозной 
Примерный перечень критериев

прогнозной оценки коммерческого потенциала кинопроекта

\begin{tabular}{|c|c|c|}
\hline Наименование критериев & \begin{tabular}{|c|} 
Вес \\
критерия в \\
подгруппе \\
\end{tabular} & \begin{tabular}{|c|} 
Вес \\
критерия \\
в целом \\
\end{tabular} \\
\hline 1 & 2 & 3 \\
\hline 1.1. Популярность литературной основы & 0,099 & 0,043 \\
\hline 1.2. Наличие интересного героя (героев) & 0,117 & 0,050 \\
\hline 1.3. Мотивированность действий основных персонажей & 0,103 & 0,044 \\
\hline 1.4. Острота конфликтной ситуации (интрига) & 0,107 & 0,046 \\
\hline 1.5. Динамичность развития событий & 0,091 & 0,039 \\
\hline 1.6. Логическая обусловленность развития событий & 0,085 & 0,037 \\
\hline 1.7. Качество диалогов & 0,107 & 0,046 \\
\hline 1.8. Название фильма (привлекательность для зрителя) & 0,087 & 0,038 \\
\hline 1.9. Финал фильма & 0,117 & 0,050 \\
\hline $\begin{array}{l}\text { 1.10. Присутствие в фильме параллельных сюжетных } \\
\text { линий, способных усилить зрительский интерес }\end{array}$ & 0,083 & 0,036 \\
\hline Итого по группе 1: & 1,000 & 0,429 \\
\hline 2.1. Актуальность идеи (темы) фильма & 0,215 & 0,046 \\
\hline $\begin{array}{l}\text { 2.2. Соответствие основной темы фильма интересам } \\
\text { и запросам целевой зрительской аудитории }\end{array}$ & 0,215 & 0,046 \\
\hline 2.3. Популярность жанра фильма & 0,203 & 0,044 \\
\hline 2.4. Определенность авторской позиции & 0,183 & 0,039 \\
\hline 2.5. Соответствие структуры сценария требованиям жанра & 0,183 & 0,039 \\
\hline Итого по группе 2: & 1,000 & 0,214 \\
\hline 3.1. Продюсер фильма & 0,163 & 0,044 \\
\hline 3.2. Автор сценария & 0,169 & 0,046 \\
\hline 3.3. Автор оригинальной музыки к фильму & 0,138 & 0,038 \\
\hline 3.4. Режиссер-постановщик & 0,185 & 0,050 \\
\hline 3.5. Оператор-постановщик & 0,169 & 0,046 \\
\hline 3.6. Актеры-исполнители главных ролей & 0,176 & 0,048 \\
\hline Итого по группе 3: & 1,000 & 0,272 \\
\hline 4.1. Дистрибьютор & 0,495 & 0,042 \\
\hline 4.2. Стратегия продвижения фильма & 0,505 & 0,043 \\
\hline Итого по группе 4: & 1,000 & 0,085 \\
\hline
\end{tabular}

оценки коммерческого потенциала кинопроекта. Изначально в состав вербально-числовой шкалы входят содержательное описание градаций шкалы (столбец 1) и числовые значения соответствующие каждой из градаций шкалы (столбец 2). 3начения столбца 3 рассчитаны путем умножения численных значений градаций (столбец 2) на общее количество оцениваемых критериев, т.е. 23.

Для количественного выражения уровней коммерческого потенциала кинопроекта предлагается следующий подход: данные уровни кинопосещаемости рассчитываются на основе производственной себестоимости фильма с учетом целевой установки в части коммерческой эффективности кинопроекта и схемы прокатных отчислений. Согласно данному подходу:

1) Фильм с очень высоким коммерческим потенциалом аккумулирует валовые кассовые сборы, обеспечивающие состояние планируемой прибыльности проекта. К примеру, продюсер занимается разработкой кинопроекта с производственной себестоимостью 30 млн рублей и планирует получить чистую прибыль от кинотеатрального проката в размере $20 \%$ на инвестиции. В этом случае, с учетом существующей схемы прокатных отчислений ${ }^{1}$, валовые кассовые сборы фильма должны составить 90 млн рублей.

2) Кинофильм с высоким коммерческим потенииалом акку мулирует валовые кассовые сборы, обеспечивающие состояние безубыточности проекта. В рамках условного проекта сборы должны составить 75 млн рублей.

3) Кинофильм со средним коммерческим потенциалом аккумулирует валовые кассовые сборы, обеспечивающие двукратную стоимость создания фильма. В рамках условного проекта сборы должны составить 60 млн рублей.

4) Кинофильм с низким коммерческим потенииалом аккумулирует валовые кассовые сборы, равные стоимости создания фильма. В рамках условного проекта сборы должны составить 30 млн рублей.

5) Кинофильм с очень низким коммерческим потенииалом аккумулирует валовые кассовые сборы ниже стоимости создания фильма. В рамках условного проекта сборы должны составить менее 30 млн рублей.

Завершением работы экспертов является формулирование предложений, принятие которых будет способствовать повышению коммерческого потенциала кинопроекта.

Процедура опроса экспертов. Опрос экспертов производится в соответствии с последовательной процедурой итеративного типа $[2,9,12]$, которая предполагает поочередное включение 
Модифицированная вербально-числовая шкала Харрингтона для проведения прогнозной оценки коммерческого потенциала кинопроекта

\begin{tabular}{|c|c|c|c|}
\hline $\begin{array}{c}\text { Содержательное } \\
\text { описание градаций }\end{array}$ & $\begin{array}{c}\text { Численное } \\
\text { значение }\end{array}$ & $\begin{array}{c}\text { Количество } \\
\text { критериев }\end{array}$ & $\begin{array}{c}\text { уровни } \\
\text { комерческого } \\
\text { потенциала } \\
\text { кинопроекта }\end{array}$ \\
\hline 1 & 2 & 3 & 4 \\
\hline Очень высокая & $0,8-1,0$ & $19-23$ & Очень высокий \\
\hline Высокая & $0,64-0,8$ & $14-18$ & Высокий \\
\hline Средняя & $0,37-0,64$ & $9-13$ & Средний \\
\hline Низкая & $0,2-0,37$ & $5-8$ & Низкий \\
\hline Очень низкая & $0,0-0,2$ & Менее 5 & Очень низкий \\
\hline
\end{tabular}

в опрос большего числа экспертов, получение каждым экспертом на каждой итерации информации только одного (вновь вводимого) эксперта, завершение опроса при стабилизации суждений экспертов. Таким образом, каждый эксперт только один раз, в момент ввода, представляет информацию, обосновывающую его начальное суждение; в дальнейшем он только получает данные от других экспертов и корректирует свое суждение. После каждого этапа группа управления экспертизой анализирует степень изменения мнений экспертов по сравнению с предыдущим туром; если существенного изменения мнений не происходит, опрос завершается.

3) Обработка, анализ и интерпретаиия результатов экспертной оценки. В процессе анализа и обработки результаты экспертного опроса должны характеризовать уровни выявленного коммерческого потенциала кинопроекта, вероятность наступления таких событий, рассчитанные как доли экспертов каждой из подгрупп ко всем экспертам.

Прогнозируемое (ожидаемое) значение валовых сборов фильма есть математическое ожидание коммерческого успеха кинофильма, рассчитываемое как взвешенная сумма уровней коммерческого потенциала, которые устанавливаются для кинопроекта, с весами, равными вероятности наступления соответствующих событий.

Результаты проведенной оценки используются в дальнейшем при принятии решения о целесообразности реализации кинопроекта. Допустим, проведен экспертный опрос, в котором приняли участие 8 экспертов. Оценка проводилась в соответствии со шкалой коммерческого успеха фильмов, представленной ранее.
В Табл. 3 представлены результаты опроса. Из Табл. 3 следует что исход такого события, как получение валовых кассовых сборов, соответствующих производственной себестоимости кинофильма и ниже - 30 млн рублей - оценивается экспертами с нулевой вероятностью; соответствующих уровню в 60 млн рублей - с вероятностью 0,125; обеспечивающих состояние безубыточности проекта 75 млн рублей - с вероятностью 0,250 ; обеспечивающих получение чистой прибыли в размере $20 \%$ на инвестиции - 90 млн рублей с вероятностью 0,625. Ниже представлен расчет ожидаемого значения валовых кассовых сборов на основе данных Табл. 3, а также расчет показателей коммерческой эффективности кинопроекта (Табл. 4).

1. $\mathrm{E}$ (валовые кассовые сборы $)=(0,000 * 30,00 \mathrm{MлH})+$

$\left(0,125^{\star} 60,00\right.$ млн $)+\left(0,250^{\star} 75,00\right.$ млн $)+\left(0,625^{\star} 90,00\right.$ млн $)$

$=0+7,50 \mathrm{млн}+18,75 \mathrm{млн}+56,25 \mathrm{млн}=82,50$ млн рублей.

2. Кассовые сборы за минусом отчислений кинотеатрам и дист-

рибьютору $=82,50$ млн $-41,25$ млн (50 \%) - 8,25 млн (10\%)

= 33,00 млн рублей.

Таким образом, ожидаемые кассовые сборы от кинотеатрального показа за минусом отчислений кинотеатрам и дистрибьютору покрывают все затраты по производству кинофильма и ожидаемая прибыль кинопроекта составляет 3 млн рублей или $10 \%$ от вложений в производство кинофильма. Для расчета интегральных показателей коммерческой эффективности кинопроекта допустим, что число периодов равно $2(\mathrm{n}=2)$. В этом случае внутренняя норма доходности инвестиций (IRR) составляет $4,8809 \%$. Следовательно, при ставке дисконтирования ниже yстановленного значения IRR чистый дисконтированный доход (NPV) имеет положительное значение (см. Табл. 4). Кроме того, при этом также выполняются другие условия приемлемости коммерческой эффективности кинопроекта, в связи с чем проект можно признать целесообразным.

Однако на практике возможны ситуации, когда одни критерии эффективности свидетельствуют о приемлемости проекта, а на основе других могут быть сделаны диаметрально противоположные выводы [6]. В этих условиях можно ориентироваться на какой-то один или несколько критериев, наиболее важных для руководства предприятия, либо использовать другие возможности для принятия обоснованных инвестиционных решений.

\section{Процедура принятия управленческого решения} о целесообразности реализации кинопроекта

Представление процесса разработки и принятия управленчес- 
Агрегация результатов экспертной оценки коммерческого потенциала кинопроекта (пример)

\begin{tabular}{|c|c|c|c|c|}
\hline $\begin{array}{c}\text { Оценка } \\
\text { коммерческого } \\
\text { потенциала } \\
\text { кинопроекта }\end{array}$ & $\begin{array}{c}\text { Очень низкий } \\
\text { и низкий } \\
\text { потенциал } \\
(30 \text { млн руб.) }\end{array}$ & $\begin{array}{c}\text { Средний } \\
\text { потенциал } \\
(60 \text { млн руб.) }\end{array}$ & $\begin{array}{c}\text { Высокий } \\
\text { потенциал } \\
(75 \text { млн руб. })\end{array}$ & $\begin{array}{c}\text { Очень } \\
\text { высокий } \\
\text { потенциал } \\
(90 \text { млн руб.) }\end{array}$ \\
\hline $\begin{array}{c}\text { Количество } \\
\text { экспертов, } \\
\text { вошедших } \\
\text { в подгруппу }\end{array}$ & 0 & 1 & 2 & 5 \\
\hline $\begin{array}{c}\text { Доля экспертов } \\
\text { подгруппы } \\
\text { в общем } \\
\text { количестве } \\
\text { экспертов }\end{array}$ & 0,000 & 0,125 & 0,250 & 0,625 \\
\hline
\end{tabular}

Показатели коммерческой эффективности кинопроекта

\begin{tabular}{|l|c|}
\hline \multicolumn{1}{|c|}{ Показатель } & 3начение \\
\hline Производственная себестоимость фильма (тыс. руб.) & 30000 \\
\hline $\begin{array}{l}\text { Ожидаемые кассовые сборы за минусом отчислений кинотеатрам } \\
\text { и дистрибьютору (тыс. руб.) }\end{array}$ & 33000 \\
\hline $\begin{array}{l}\text { Ожидаемая прибыль от производства } \\
\text { и реализации фильма (тыс. руб.) }\end{array}$ & 3000 \\
\hline Число периодов (год) & 2 \\
\hline Внутренняя норма доходности (IRR) (\%) & 4,8809 \\
\hline $\begin{array}{l}\text { Чистый дисконтированный доход (NPV) } \\
\text { при ставке дисконтирования 4\% (тыс. руб.) }\end{array}$ & 510,3 \\
\hline Индекс прибыльности (РI) при ставке дисконтирования 4\% & 1,0170 \\
\hline Срок окупаемости (РP) (год) при ставке дисконтирования 4\% & 1 \\
\hline
\end{tabular}

кого решения о целесообразности реализации кинопроекта в виде многошаговой процедуры позволяет использовать для нахождения рационального решения принцип оптимальности Беллмана. Согласно данному принципу «оптимальная стратегия обладает тем свойством, что, каковы бы ни были первоначальное состояние и первоначальное решение, последующее решение должно определять оптимальную стратегию относительно состояния, полученного в результате первоначального решения» [1].

Ниже изложена процедура принятия рационального управленческого решения о целесообразности реализации кинопроекта, основанная на принципе оптимальности Беллмана и методе построения дерева решений.

Дерево решений - это графическое изображение процесса принятия решений, в котором отражены альтернативные решения альтернативные состояния внешней среды, соответствующие вероятности и исходы для любых комбинаций альтернатив и состояний внешней среды $[7,10,11]$. На дереве решений каждая ветвь, представляющая собой либо существующий вариант действий, либо возможное последствие выбранного действия, делится

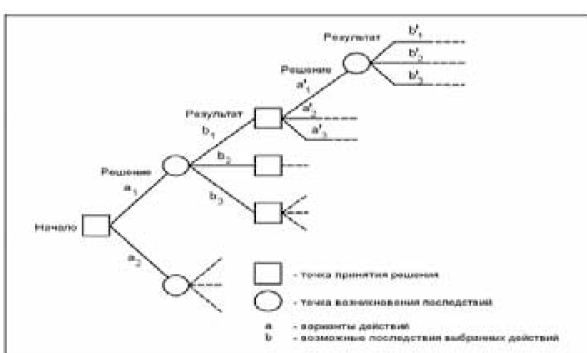

Puc. 3.

Общий вид дерева решений в определенных точках на совокупность других ветвей (Рuc. 3).

Такие точки (или узлы) бывают двух видов: а) точки принятия реше ний, в которых возникает несколько вариантов действий; б) точки возникновения последствий, в которых появляется несколько возможных последствий выбранных действий.

Разграничение узлов необходимо, так как лицо, принимающее решение, может влиять только на выбор решения, а относительно его исходов ему остается лишь вычислять вероятности их появления, т.е. здесь выбор осуществляет «природа».

Точки принятия решений обозначают в виде квадратов, а точки возникновения возможных последствий - в виде кругов. Количество точек принятия решений и точек возникновения последствий может быть каким угодно, а, значит, различных ветвей на дереве принятия решений может быть сколь угодное множество. При этом они могут иметь неодинаковое количество точек принятия решения и возникновения последствий. Каждая ветвь, исходящая из точки принятия решения, представляет собой возможные варианты действий (например, $\mathrm{a}_{1}$ и $\mathrm{a}_{2}$ на Puc. 3). Далее ветвь возможного варианта действия, проходя через точку возникновения последствий, распадается на несколько результатов действий (например, $\mathrm{b}_{1}, \mathrm{~b}_{2}$ и $\mathrm{b}_{3}$ на Puc. 3). Необходимо отметить, что каждое последствие имеет свою оценку вероятности, а также количественную (денежную) оценку результата. 


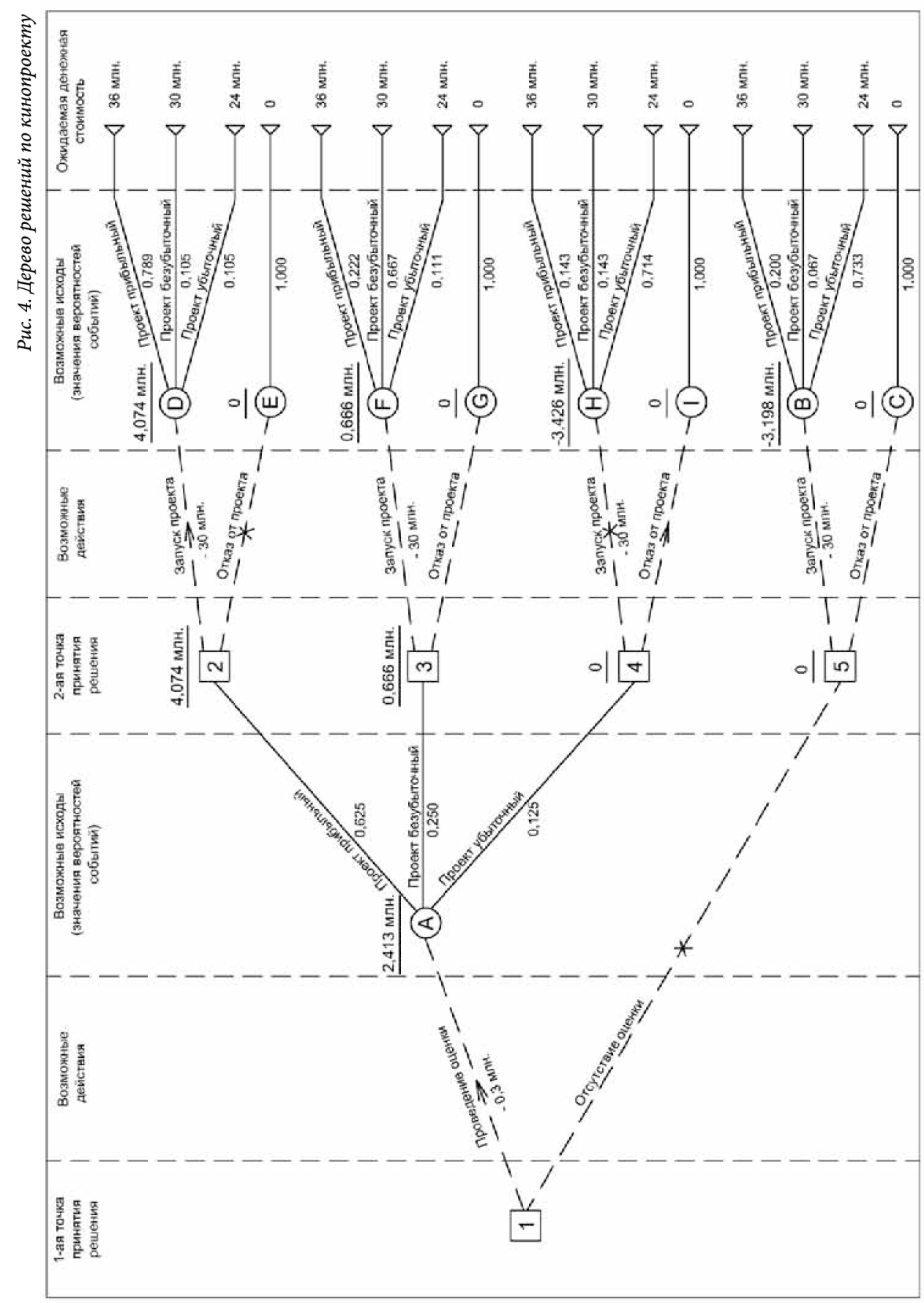

При анализе проблемы, по которой принимается решение, путем прямого хода осуществляется структуризация проблемы, т.е. разбитие ее на совокупность логически связанных вариантов решений и их постедствий, а также присвоение им вероятностных и количественных результатов. Структурировав проблему прямым ходом, ее подвергают анализу обратным ходом (справа налево) и оценивают существующие варианты решений на основе расчета ожидаемого значения.

Для использования метода построения дерева решений для нахождения рационального управленческого решения о целесообразности реализации кинопроекта необходимы следующие данные:

- множество вариантов решений для лица, принимающего решение, т.е. продюсера. В данном случае таковыми являются:

a) проведение оценки коммерческого потенциала кинопроекта;

б) запуск проекта в производство без проведения оценки;

в) отказ от проекта вообще;

- множество возможных исходов и вероятностей этих исходов, т.е. количественные вероятностные прогнозной оценки коммерческого потенциала кинопроекта;

- результаты при различных вариантах принимаемых решений и исходов.

Искомыми решениями являются: а) решение о целесообразности реализации кинопроекта; б) решение о нецелесообразности реализации кинопроекта с возможностью внесения корректирующих мер в целях повышения коммерческого потенциала кинопроекта и проведения повторной экспертной оценки.

Рассмотрим пример использования метода построения дерева решений при анализе кинопроекта. Первоначальное решение, которое необходимо принять продюсеру, - проводить ли такую оценку вообще? Допустим, стоимость создания фильма составляет 30 млн рублей, а затраты на проведение оценки - не более 0,3 млн рублей. Если не проводить оценку, то решение о целесообразности реализации кинопроекта можно принять незамедлительно. Допустим, продюсер принял решение провести экспертную оценку коммерческого потенциала кинопроекта. Результаты данной оценки представлены в Табл. 3.

Для построения дерева необходимы данные, характеризующие вероятности исходов в случае запуска фильма в производство без проведения оценки. В качестве таковых предлагается использовать статистику проката российских фильмов (желательно без учета фильмов, по которым проводилась прогнозная оценка). Для этого рассчитываются соотношения количества 
фильмов с соответствующими валовыми кассовыми сборами к общему количеству российских фильмов, вышедших в прокат в 2008 году [4,5]. Полученные значения - есть вероятности, характеризующие то или иное событие. Например, в 2008 году исход такого события, как получение валовых кассовых сборов до 60 млн рублей, может быть оценен с вероятностью 0,733; от 60 до 90 млн рублей - с вероятностью 0,067; более 90 млн рублей $-0,200$

Рассмотрим Рuc. 4. В узле 1 продюсер принимает решение проводить оценку коммерческого потенциала кинопроекта, либо не проводить. Рассмотрим сначала второй из перечисленных вариантов возможных действий. В узле 5 продюсер принимает решение приступить к реализации проекта, либо отказаться от него. Если продюсер приступает к его реализации, то следующий выбор (в узле «В») принадлежит «природе». Значения вероятностей в этом случае составляют $0,733,0,067$ и 0,200 (статистика проката российских фильмов в 2008 году).

У конца каждой ветви указана ожидаемая денежная стоимость - объем валовых кассовых сборов за минусом отчислений кинотеатрам и дистрибьютору. Здесь возможны следующие варианты развития событий:

Вариант 1. «Проект прибыльный». В данном случае валовые кассовые сборы составляют, как минимум, 90 млн рублей, а с учетом отчислений кинотеатрам и дистрибьютору - 36 млн рублей.

Вариант 2. «Проект безубыточный». В данном случае валовые кассовые сборы составляют, как минимум, 75 млн рублей, а с учетом отчислений кинотеатрам и дистрибьютору - 30 млн рублей.

Вариант 3. «Проект убыточный». В данном случае валовые кассовые сборы составляют, как минимум, 60 млн рублей, а с учетом отчислений кинотеатрам и дистрибьютору - 24 млн рублей.

Расчет ожидаемого значения исхода узла «В»:

E $(B)=\left(0,200^{\star} 36000\right.$ тыс. $)+\left(0,067^{\star} 30000\right.$ тыс. $)+\left(0,733^{\star} 24000\right.$ тыс. $)$ $=7200$ тыс. +2010 тыс. +17592 тыс. $=26802$ тыс. рублей

NE (B) = 26802 тыс. -30000 тыс. $=$ (минус) 3198 тыс. рублей

Ожидаемое значение узла «С», и, соответственно, варианта «отказ от проекта», равно нулю.

$$
\begin{aligned}
& \mathrm{E}(\mathrm{C})=0 \\
& \mathrm{NE}(\mathrm{C})=0
\end{aligned}
$$

Таким образом, в узле 5 максимальное ожидаемое значение равно нулю (поскольку 0 больше, чем (минус) 3198 тыс. рублей), и в данном случае рациональным решением является отказ от проекта. Необходимо отметить, что в случае принятия такого решения продюсер готов отказаться от него за любую сумму, превышающую рассчитанное ожидаемое значение, т.е. нуль.

Теперь перейдем к рассмотрению второго варианта возможных действий - проведению оценки коммерческого потенциала кинопроекта. Прежде всего, чтобы достигнуть узла «А», нужно заплатить 0,3 млн рублей. Однако значение этого узла не очевидно, поскольку в нем открывается несколько альтернатив - результаты экспертной оценки. Для того чтобы определить фактическое значение узла, необходимо рассмотреть все правые концы ветвей дерева, связанные с этим узлом, и двигаться к нему в обратном направлении. Но прежде чем осуществить эти действия, необходимо принять во внимание результаты предыдущих оценок коммерческого потенциала кинопроектов. Допустим, что до анализируемого проекта уже проводилось 35 оценок. Статистика этих оценок и фактические данные проката по оцененным фильмам представлены в Табл. 5. Из таблицы следует, что из общего числа проектов, которые были признаны экспертами как «прибыльные», 15 проектов в итоге таковыми и оказались, 2 проекта - оказались «безубыточными», а 2 проекта - «убыточными».

Таким образом, можно рассчитать следующие вероятности:

P (проект прибыльный/проект прибыльный $)=15 / 19=0,789$

$\mathrm{P}$ (проект прибыльный/проект безубыточный $)=2 / 19=0,105$

$\mathrm{P}$ (проект прибыльный/проект убыточный $)=2 / 19=0,105$

$\mathrm{P}$ (проект безубыточный/проект прибыльный) $=2 / 9=0,222$

$\mathrm{P}$ (проект безубыточный/проект безубыточный $)=6 / 9=0,667$

$\mathrm{P}$ (проект безубыточный/проект убыточный $)=1 / 9=0,111$

$\mathrm{P}$ (проект убыточный/проект прибыльный $)=1 / 7=0,143$

$\mathrm{P}$ (проект убыточный/проект безубыточный $)=1 / 7=0,143$

$\mathrm{P}$ (проект убыточный/проект убыточный $)=5 / 7=0,714$

Теперь предположим, что достигнуты узлы «D», «E», «F», «G», «Н» и «I». Сначала необходимо установить ожидаемые значения по каждому из возможных последствий в каждом из узлов. Для этого необходимо провести следующие вычисления:

$E(D)=(0,789 * 36000$ тыс. $)+\left(0,105^{\star} 30000\right.$ тыс. $)+\left(0,105^{\star} 24000\right.$ тыс. $)$ $=28404$ тыс. +3150 тыс. +2520 тыс. $=34074$ тыс. рублей

$\mathrm{NE}(\mathrm{D})=34074$ тыс. -30000 тыс. $=4074$ тыс. рублей 
$\mathrm{E}(\mathrm{E})=0$

$\mathrm{NE}(\mathrm{E})=0$

$E(F)=\left(0,222^{\star} 36000\right.$ тыс. $)+\left(0,667^{\star} 30000\right.$ тыс. $)+\left(0,111^{\star} 24000\right.$ тыс. $)$

$=7992$ тыс. +20010 тыс. +2664 тыс. $=30666$ тыс. рублей

$\mathrm{NE}(\mathrm{F})=30666$ тыс. -30000 тыс. $=666$ тыс. рублей

$E(G)=0$

$\mathrm{NE}(\mathrm{G})=0$

$E(H)=\left(0,143^{\star} 36000\right.$ тыс. $)+\left(0,143^{\star} 30000\right.$ тыс. $)+\left(0,714^{\star} 24000\right.$ тыс. $)$ $=5148$ тыс. +4290 тыс. +17136 тыс. $=26574$ тыс. рублей

$\mathrm{NE}(\mathrm{H})=26574$ тыс. -30000 тыс. $=($ минус $) 3426$ тыс. рублей

$\mathrm{E}(\mathrm{I})=0$

$\mathrm{NE}(\mathrm{I})=0$

Предположим, что теперь достигнут узел 2 и нужно принять одно из двух решений: запускать фильм в производство или отказаться от проекта. Решение о запуске кинофильма в производство означает, что достигается вершина «D» и это приводит к ожидае мому значению, равному 4074 тыс. рублей. Решение отказаться от проекта приводит к нулевому исходу (узел «Е»). Принимается первое решение, поскольку 4074 тыс. рублей больше, чем нуль.

В узле 3 также осуществляется выбор наилучшего решения. Решение о запуске кинофильма в производство означает, что достигается узел «F» и это приводит ожидаемому значению, равному 666 тыс. рублей. Решение отказаться от проекта приводит к нулевому исходу (узел «G»). Принимается первое решение, поскольку 666 тыс. рублей больше, чем нуль.

В узле 4 осуществляются аналогичные действия. Решение о запуске кинофильма в производство означает, что достигается вершина «Н» и это приводит к потерям - (минус) 3426 тыс. рублей. Решение отказаться от проекта приводит к нулевому исходу (узел «I»), и здесь принимается второе решение.

Сделаем еще один шаг в направлении, обратном течению времени, и оценим стоимость узла «А». Из данного узла в зависимости от итогов экспертной оценки можно попасть в любой из узлов 2, 3 и 4 (см. Табл. 3). Чтобы найти значение узла, нужно сделать следующие вычисления:

$\mathrm{E}(\mathrm{A})=\left(0,625^{\star} 4074000\right)+\left(0,250^{*} 666000\right)+\left(0,125^{\star} 0\right)=$

$2546250+166500+0=2712750$ рублей

$\mathrm{NE}(\mathrm{A})=2712750-300000=2412750$ рублей

Теперь необходимо проанализировать решения, которые принимаются в узле 1. Отказ от проведения оценки приводит к нулевой стоимости. Решение о проведении оценки коммерческого потенциала кинопроекта - к чистому ожидаемому значению в размере 2,413 млн рублей. На Рuc. 4 посредством направляющих стрелок показана последовательность решений, ведущая к максимальной денежной стоимости и образующая оптимальную стратегию в отношении кинопроекта. Так, в узле 1 целесообразно провести оценку коммерческого потенциала кинопроекта. При «исходе» экспертной оценки - «проект прибыльный» в узле 2 рациональным решением будет запуск проекта; при «исходе» - «проект безубыточный» в узле 3 - по усмотрению продюсера: запустить проект в производство либо отказаться от него; при «исходе» - «проект убыточный» в узле 4 - отказаться от проекта. Таким образом, анализируя дерево решений, продюсер может сформулировать оптимальную стратегию в отношении разрабатываемого кинопроекта. Для рассматриваемого примера ее можно определить следующим образом: следует провести прогнозную оценку коммерческого потенциала кинопроекта и приступить к производству фильма только при «соответствующем разбросе мнений экспертов».

По итогам построения дерева решений ожидаемая прибыль от реализации проекта с учетом затрат на проведение прогнозной оценки (0,3 млн рублей) составила около 2,413 млн рублей. Таким образом, получены сопоставимые результаты.

На основе построенного дерева можно сделать заключение по поводу эффекта от проведения прогнозной оценки коммерческого потенциала кинопроекта. Так из Рuc. 4 следует, что значение узла «B»- есть ожидаемые потери, которые продюсер может понести при реализации проекта в случае материализации нерационального решения - запуска проекта в производство без проведения оценки. Согласно представленному примеру, ожидаемые потери составляют 3198 тыс. рублей, что более чем в 10 раз превышает расходы на проведение самой экспертной оценки (0,3 млн рублей).

В заключение следует отметить, что для того, чтобы стать жизнеспособным и прибыльным, кинобизнес нуждается не только 
Таблица 5

Итоги предыдущих оценок и результаты реализации кинопроектов

\begin{tabular}{|c|c|c|c|c|}
\hline \multirow{2}{*}{$\begin{array}{c}\text { Результаты } \\
\text { экспертного } \\
\text { опроса } \\
\end{array}$} & \multicolumn{3}{|c|}{ Фактические результаты } & \multirow[t]{2}{*}{ Всего } \\
\hline & $\begin{array}{c}\text { Проект } \\
\text { прибыльный }\end{array}$ & $\begin{array}{c}\text { Проект } \\
\text { безубыточный }\end{array}$ & $\begin{array}{c}\text { Проект } \\
\text { убыточный }\end{array}$ & \\
\hline 1 & 2 & 3 & 4 & 5 \\
\hline $\begin{array}{c}\text { Проект } \\
\text { прибыльный }\end{array}$ & 15 & 2 & 2 & 19 \\
\hline $\begin{array}{c}\text { Проект } \\
\text { безубыточный }\end{array}$ & 2 & 6 & 1 & 9 \\
\hline \multirow[t]{2}{*}{$\begin{array}{c}\text { Проект } \\
\text { убыточный }\end{array}$} & 1 & 1 & 5 & 7 \\
\hline & 18 & 9 & 8 & 35 \\
\hline
\end{tabular}

и не столько в деньгах. Успех во многом зависит от эффективного управления, посредством которого продюсер - ключевое лицо в кинематографическом процессе - трезво оценивает ситуацию, ясно видит перспективу и возможные проблемы, вырабатывая инструментарий для их преодоления в будущем, а также принимает рациональные управленческие решения в таком сложном процессе, как создание и продвижение кинофильма.

\section{Выводы:}

1. В рыночных условиях прогнозирование коммерческого потенциала кинопроекта на ранних этапах фильмопроизводства следует рассматривать в качестве инструмента киномаркетинга, бизнес-планирования и снижения инвестиционных рисков в сфере кинопроизводства.

2. В числе основных факторов коммерческого успеха кинофильмов можно выделить: востребованность кинофильма у зрителей, его художественную ценность, деловую и профессиональную репутацию создателей кинофильма, адекватную финансовую базу для производства и продвижения кинофильма, а также наличие активной стратегии продвижения кинофильма, обеспечивающей максимальный охват целевой зрительской аудитории.

3. Прогнозирование коммерческого потенциала кинопроекта рекомендуется осуществлять посредством морфологического анализа объекта исследования (сценарий кинофильма и кинопроект в целом) с использованием метода экспертных оценок, а именно последовательной процедуры итеративного типа, позволяющей получать устойчивые суждения экспертов при эффективной системе обмена информацией между ними, а также эмпирически определять их оптимальное число и количество итераций при условии достижения цели экспертизы. В качестве оценочной шкалы коммерческого успеха кинофильмов целесообразно использовать определенные уровни кинопосещаемости, предполагающие целевую установку в части коммерческой эффективности разрабатываемых кинопроектов. Результаты экспертной оценки представляются в виде распределения экспертов в зависимости от их мнений, что является обоснованным, учитывая вероятностную природу коммерческого успеха фильмов.

4. Представление процесса разработки и принятия управленческого решения о целесообразности реализации кинопроекта в виде многошаговой процедуры позволяет использовать для нахождения рационального решения принцип оптимальности Беллмана и метод построения дерева решений. Использование предложенного инструментария принятия рационального управленческого решения о целесообразности реализации кинопроекта приводит к выстраиванию эффективной модели принятия решений, способствует снижению неопределенности при принятии инвестиционных решений, качественному улучшению различных направлений кинопроизводящих предприятий.

\section{ЛИТЕРАТУРА:}

1. Беллман P., Калаба Р. Динамическое программирование и современная теория управления.

2. Бурков В.Н., Панкова Л.А., Шнейдерман М.В. Получение и анализ экспертной информаиии М.: Институт проблем управления, 1980.

3. Голубков Е.П. Технология и принятие управленческих ремений. М.: Издательство

4. Киностатистика - 2007: Статистический сборник. М.: МАКС Пресс, 2008.

5. Киностатистика - 2008. М.: Роликс, 2009.

6. Ковалев В.В. Методы оценки инвестиционных проектов. М.: Финансы и статистика, 1998

7. Косоруков О.А. Методы количественного анализа в бизнесе. М.: ИНФРА-М, 2005.

8. Основы продосерства. Аудиовизуальная сфера / Под ред. Г.П. Иванова, П.К. Огурчикова, В.И. Сидоренко. М.: ЮНИТИ-ДАНА, 2003.

9. Панкова Л.А., Петровский А.М., Шнейдерман М.В. Организаиия экспертизы и анализ экспертной информации. М.: Наука, 1984.

10. Разработка управленческих ремений / Под ред. Ю.Г. Учителя, А.И. Терновой, К.И. Тернова.

1. Шапкин А.С., Мазаева Н.П. Математические методы и модели исследования операиий:

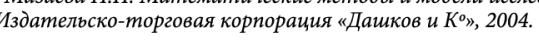

12. Шнейдерман М. В. Об одной модели проиедуры экспертного опроса // Экспертние очешки и восприятие искусства. Труды 48. М.: Министерство культуры РСФСР, НИИ культуриы 1977. 